\title{
THE POTENTIAL OF CROATIA AS AN ATTRACTIVE TOURIST DESTINATION FOR SENIOR TOURISTS
}

\author{
Damir Pavlović \\ Marko Koščak \\ Nikolina Šerić
}

https://doi.org/10.20867/tosee.05.53

\begin{abstract}
Purpose - The main purpose of this paper was to evaluate the current supply of composite tourist products in Croatia in relation to the needs of older people's needs with a focus on the European market and to identify all shortcomings and disparities in order to make recommendations for a more efficient development of tourism products within Croatia in function of the extension of the tourist season.

Methodology - The results were obtained by using a mixed methodology by combining quantitative (TOMAS research from 2017 and TOURage project from 2014) and qualitative (semistructured interviews with relevant tourism industry subjects) data processing methods using comparative analysis within the match model.

Findings - Findings show that the quality of the landscape, security, general services, hotel accommodation and transport according to the rating of all segments of tourists who visited Croatia above the quality expected of senior tourists when choosing their travel destination. Particular attention should be paid to the safety, accommodation comfort, medical accessibility, specific cultural and less challenging adventure experiences within the flexible packages offered on the dominant EU markets of Germany, France, the UK and Scandinavia. Croatia as a tourist destination, with certain improvements and adjustments of the tourist product components, has a predisposition for a stronger market penetration that covers the segment of the senior tourists. Keywords Senior tourists, tourist supply components, match model, season extending
\end{abstract}

\section{INTRODUCTION}

According to EUROSTAT's demographic survey, more than 99.5 million people in the European Union in 2017 were over 65, representing about $19.4 \%$ of the total population. 1 out of 5 European residents will belong to the age group 65+ by 2020, and almost 1 to 4 to 2030. Current demographic trends in the European Union show that the percentage of older people is likely to rise by $30 \%$ by 2060 . Changes in the age structure of the population will in many respects be one of the essential characteristics of the $21 \mathrm{st}$ century, which can result in numerous implications for society as a whole. This can be reflected in the labour and financial markets, housing, transport and social protection as well as changes in family structure and intergenerational relationships (United Nations 2015). The United Nations (2010) describes aging population as the deepest demographic change in history, and that age group will grow faster than others. Demographic aging is a challenge that many countries face (Howse 2014). Nevertheless, Harper (2014) states that future generations of older adults will have a higher level of human capital in terms of education, skills and abilities as well as better health potential, which will enable them to remain active, productive and thus contribute to society more 
ToSEE - Tourism in Southern and Eastern Europe, Vol. 5, pp. 533-545, 2019

D. Pavlović, M. Koščak, N. Šerić: THE POTENTIAL OF CROATIA AS AN ATTRACTIVE TOURIST ...

long-term. One of the important prerequisites for achieving a better health profile may be to improve the quality of life through travel (Patterson and Balderas (2018). For the tourism industry, older people are impelled as a segment of the primary market, both in terms of the number of trips they make and in terms of the size of their expenditures (Fleischer and Pizam, 2002). Glover and Prideaux (2009) predict that the dominance of the baby boom generation will continue to be a factor in the design of tourism products and services.

This study covers population research made by people over the age of 65 who are mostly retired. These older tourists make up more than $20 \%$ of European leisure travel, which illustrates the importance of this group ${ }^{1}$.

Croatia is a country with still pretty high seasonality regarding tourist arrivals, and thus tourist activities in general. This situation makes the business of existing tourist subjects quite difficult, which in the struggle for such profitability must attain income that covers the whole year in the active part of the year. They often force high prices or save on input costs (labour force, poorer quality of food), thus jeopardizing un-competitiveness, both in the demand market and on the labour market where harder are finding workforce. Thus, the extension of the tourist season is a strategic need for Croatian tourism. Although in the follow-up to this paper, more attention will be given to the numerous characteristics of the segment of older people's tourism demand, one of which - flexible provision of leisure time, under certain conditions, can significantly influence the extension of the tourist season.

So far In Croatia, there have been no serious publications to address the phenomenon of senior tourism concepts, neither from the aspect of market analysis of the interest and potential of demand for that segment, nor from the aspect of the domestic reception capacity analysis that should meet that segment of demand. Consequently, it seems instructive in this study to consider the issue of tourism conceptuality in the form of situational analysis, on both the demand side and on the supply side, and their mutual interaction, to make certain conclusions and framework recommendations for relevant business practice in the future as well as the starting point for future deeper research of a given phenomenon

Matching of supply and demand in tourism was observed from different perspectives, such as the motivation of tourists and the choice of destination (Andreu, Kozak, Avci and Cifter, 2005, Awaritefe, 2004), perceptions and expectations of tourist destinations and tourist satisfaction with destination (Ibrahim, Essam \& Gill 2005) and the importance of attractions for attracting destinations (Formica and Uysal, 2006). Research to what extent the main components of the tourist / destination product, ie. attraction, accessibility and transport, security, accommodation and activities, image and prices meet the needs of specific market segments such as senior tourists are not so common, especially in the domain of Croatian tourism. In view of this, the following research objectives (RO) have been set in this study:

\footnotetext{
${ }^{1}$ According to EUSTAT, 2014
} 
ToSEE - Tourism in Southern and Eastern Europe, Vol. 5, pp. 533-545, 2019

D. Pavlović, M. Koščak, N. Šerić: THE POTENTIAL OF CROATIA AS AN ATTRACTIVE TOURIST ...

$\mathrm{RO}_{1}$ - Assess the current offer of composite tourism products in Croatia in relation to the needs of older people's needs with a focus on the European market and identify any shortcomings in order to make recommendations for more effective product development within Croatia in function of the extension of the tourist season.

$\mathrm{RO}_{2}$ - Assess the matching level between the perceptions of the main providers of tourist offerings in HR (the largest tourism and hotel companies in the CRO) on the quality of the most important components of the tourist product and the level of importance (expected quality) of those same components expressed by the senior tourists segment within the most important EU markets.

$\mathrm{RO}_{3}$ - Examine the matching level between the perceptions of the main providers of tourist offer in the CRO with the level of quality satisfaction that all segments of tourism evaluate within the most important components of tourist products in Croatian destinations, in order to detect any possible gap between the identity and the image of these destinations.

Following the introductory chapter of this paper, the second chapter presents the main features of the senior tourists segment within the EU emitting market, which are in the third chapter confronted with the attitudes of all visitors to the Croatian destinations regarding the satisfaction and quality of certain components of tourist product offerings. The next (fourth) chapter presents the results of the research conducted with the interpretation and discussion of the same. Consequently, in the conclusion of the paper, the answers to the set research objectives in this paper were presented and practical recommendations for future business practice in Croatian tourism as well as for future scientific research were made.

\section{SENIOR POPULATION AND TOURISM: FACTS}

In the last 20 years, there have been several researches dealing with the senior tourists concept. One of the main findings of these surveys was that the market segment of older tourists is heterogeneous, and that older consumers are not 'all the same' (Lehto et al 2002). Several studies have revealed that older passengers differ from younger passengers in several dimensions such as reasons for traveling or destination choice (Reece 2004). Patterson (2018) concluded that one of the causes of this heterogeneity and variety of tourist market seniors lies in the fact that they required a greater variety of travel opportunities than before; from soft adventurous trips that were aimed at organizing via the Internet, grouped trips where the tourist agency and the fact that they are staying in fivestar hotels for all of them.

\subsection{What makes senior tourists an important and attractive market segment?}

As a direct consequence of global aging patterns, older passengers are increasingly participating in a larger share of total spending on vacation (Sangpikul 2008; Wang et al., 2007). The increased propensity to travel will further increase in the future due to the active generation of older people who will benefit from the higher life expectancy; higher disposable income; improved health standards; a greater number of older people who are 
ToSEE - Tourism in Southern and Eastern Europe, Vol. 5, pp. 533-545, 2019

D. Pavlović, M. Koščak, N. Šerić: THE POTENTIAL OF CROATIA AS AN ATTRACTIVE TOURIST ...

used to traveling; and change of attitude towards lifesaving, available time and what it should be used (Möller et al., 2007). In the future it is anticipated that older people will become the most significant consumer group, since it will belong to the richest generation (Meiners et al., 2010). This is also related to improving the economic status and health conditions of this group (Yoon et al 2009). Most importantly, of course, older adults generally have more free time with which they can have more flexibility than is the case with younger and business-related generations. Consequently, it is logical to conclude that elderly people, with the condition of health predisposition, also have greater potential for using leisure time for travel and tourism, which is influencing the trend of growth among older populations in order to take advantage of tourist and sightseeing opportunities during the tourism season (Gu et al., 2016).

\subsection{Preferences and requirements of senior tourists}

Like every other segment of tourist demand, this segment of tourists has their own special preferences and requirements that lead first to the decision of travel itself and then to the choice of the destination of their travel and tourist activities in it. In this respect, two most important researches were conducted; the TOURage ${ }^{2}$ project in co-operation with the European Union in 2014 and the $\mathrm{CBI}^{3}$ research of 2017, which concerned the research of older people's tourist segments, their demands and expectations regarding tourism and individual segments of tourist offer in destinations. The results of these surveys show that the following segments of the tourist offer are of particular importance:

- The beauty of nature and landscape - Tourist seniors coming from the most important EU emitting areas are highly prone to the beauty of the countryside in the destination, which positively points to the marked ambivalent deflection in relation to the domicile natural environment.

- Personal safety, health protection and political stability - European senior citizens are particularly interested in health and safety. At home, they usually require high standards of safety and protection, and accordingly expect the same level during travel. Particularly important is the safety of travel (driving) to the destination and back. In addition, they are important security systems in accommodation units and their surveillance. Older tourists usually avoid insecure areas, such as areas with political disruption.

- Historical sights - For the senior tourists among the first priorities of interest are cultural and historical sights.

- High quality requirements - European senior citizens are more experienced and sophisticated tourists than previous generations. They are increasingly aware of the quality and are all demanding. Examples of quality requirements for tourist service providers are personalized and 24/7 service, friendly staff, clean, safe and wellmaintained facilities, comfortable rooms and beds, and varied and healthy meals.

\footnotetext{
2 The TOURage project is funded by Interregional Cooperation Program INTERREG IVC with the aim of improving the effectiveness of regional policies and instruments

$3 \mathrm{CBI}$, the Centre for the Promotion of Imports from developing countries (https://www.cbi.eu/marketinformation/tourism/senior-travel)
} 
ToSEE - Tourism in Southern and Eastern Europe, Vol. 5, pp. 533-545, 2019

D. Pavlović, M. Koščak, N. Šerić: THE POTENTIAL OF CROATIA AS AN ATTRACTIVE TOURIST ...

- Transport accessibility of the destination - It refers to external accessibility (facilitated transport to the destination) and internal accessibility (easy transport within the destination). Senior tourists generally have higher requirements regarding availability and communication than other age segments. This is why motor skills and disability of individual tourists have been reduced. Senior citizens with mobility constraints, for example, actively seek ramp and lifts hotels.

- Quality of accommodation in hotels - Applies to the suitability and variety of hotel facilities, above all an individualized approach (a'la carte service in restaurants rather than integral service).

- Unique experience - Generally, current trends in tourism are characterized by a more pronounced demand for unique tourist experience than it was the case with previous generations. They like to be active, learn, discover, and enjoy new experiences. Another key to hiring older tourists is to attract their senses. They tend to find a travel experience that includes the taste, touch, smell and / or the sound they remember.

- Packaged arrangements - Older tourists are more inclined to travel and package arrangements than younger age groups, mainly because they are perceived as more reliable. They want a pre-structured schedule that tells them which tourism activities they will have and when. Generally, they prefer to travel in groups of 20-25 people because they love to meet other people and feel more secure in the group.

- Longer Trips and Trips Off the Main Season - Since older tourists are not necessarily tied to school holidays or annual vacations in their active working age, their trips are extended beyond the main season. Most of their trips are carried out in terms of March to June and from September to November. About $40 \%$ of the nights spent by senior European tourists in May, June and September, which significantly extend the season. In addition, their travel lasts longer on average over younger groups; seven versus five nights).

In addition to the most important characteristics of the profile, preferences and demands of European senior tourists, it is important to mention other such as:

- $\quad$ expect the value of the service by price but also the readiness to spend more money on travel than the average, especially when it comes to new experiences;

- $\quad$ health and medical facilities;

- they prefer to travel off the main season, saving money and avoiding crowds;

- $\quad$ spend more time planning travel in relation to younger age groups.

Table 1 shows the importance of some segments of the tourist supply (tourist product) as a function of the decision of the senior tourists to travel and the choice of a specific destination. 
ToSEE - Tourism in Southern and Eastern Europe, Vol. 5, pp. 533-545, 2019

D. Pavlović, M. Koščak, N. Šerić: THE POTENTIAL OF CROATIA AS AN ATTRACTIVE TOURIST ...

Table 1: Preferential components of tourist supply for choice of destination in case of senior tourists population

\begin{tabular}{|c|c|c|}
\hline Supply components & $\begin{array}{c}\text { Average importance } \\
\text { (expected quality) for } \\
\text { senior tourists }\end{array}$ & $\begin{array}{c}\text { Average importance } \\
\text { (expected quality) for } \\
\text { senior tourists (\%) }\end{array}$ \\
\hline 1. Landscape & Average & $83,20 \%$ \\
\hline 2. Security and safety & 4,11 & $82,20 \%$ \\
\hline 3. Historical sights availability & 3,9 & $78,00 \%$ \\
\hline 4. Quality of service & 3,87 & $77,40 \%$ \\
\hline 5. Transport accessibility & 3,79 & $75,80 \%$ \\
\hline 6. Quality of hotel accommodation & 3,65 & $73,00 \%$ \\
\hline 7. Value for money & 3,64 & $72,80 \%$ \\
\hline 8. Local culture presentation & 3,61 & $72,20 \%$ \\
\hline 9. Additional experience & 3,57 & $71,40 \%$ \\
\hline 10. Health care and medical service & 3,49 & $69,80 \%$ \\
\hline
\end{tabular}

Source: Adapted by TOURage project, 2014.

From the above aggregate table it is possible to conclude that older tourists are reluctant to travel outside the main seasons to destinations with an accentuated attraction of natural landscapes and historical sights, spend more than average, spending more time on the journey provided the quality of tourist experience and personal and health safety.

Seniors are healthier and richer than previous generations and are more flexible in terms of travel time than other groups. The effects of age on tourist behaviour increasingly become the focal point of research. Numerous empirical studies of older tourists have provided evidence of the positive impact of tourist experiences on their quality of life (Uysal et al., 2012). However, they require products and services that are specifically tailored to their needs, desires and interests. They are especially interested in active vacations that combine nature, culture, soft adventure activities and encounters with locals. An increase in the interest of older people is also expected for derived products such as spa and wellness treatments. From the aspect of research in this paper as a function of tourism in Croatia, below will be presented the most important demands of the market concept of tourism in Europe.

The most important sources of information on tourism and destination are their own experiences or family members / friends. The media and social media have not yet succeeded in reaching this target group. Therefore, the providers of tourist services for this age group should use different communication channels. Since the use of the Internet is still fairly low among older people, it is also important to invest in paper brochures.

\subsection{The structure of the European market demand for the senior tourists}

About half of all European senior citizens participate in tourism, compared to $62 \%-69 \%$ of younger age groups. Of these European senior travelers, almost half of them have at least one international trip a year. Among those who do not participate, health reasons are the most common reason to stay home. 
ToSEE - Tourism in Southern and Eastern Europe, Vol. 5, pp. 533-545, 2019

D. Pavlović, M. Koščak, N. Šerić: THE POTENTIAL OF CROATIA AS AN ATTRACTIVE TOURIST ...

Among European senior tourists, those aged between 65 and 74 travel relatively much. This segment is responsible for $15 \%$ of European tourist nights, while it accounts for $12 \%$ of the population. For tourists over the age of 75 , the truth is the opposite: they make up $11 \%$ of the population, but only $7.0 \%$ of the nights spent on European tourist tourism. This is most likely due to health reasons that increase with age.

\section{Diagram1: Share of travelers over 65 in tourism in Europe by countries of origin 2014}

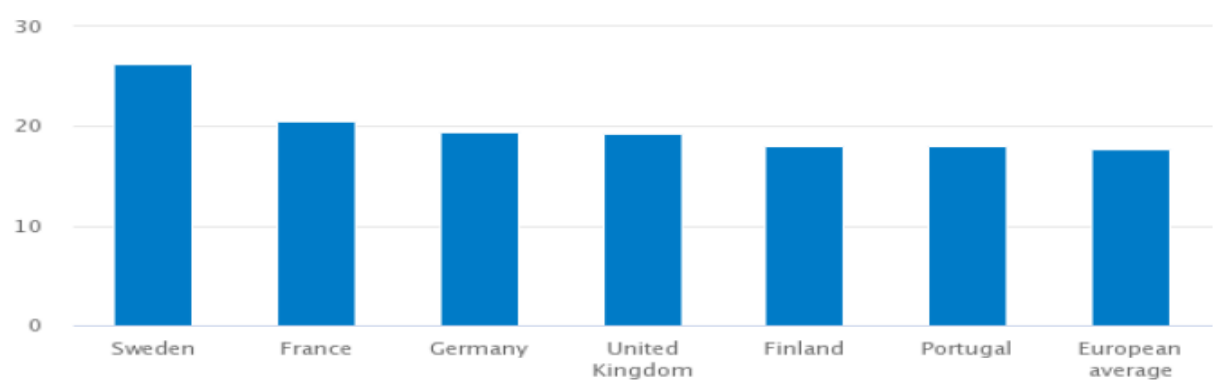

Source: Eustat 2017

The tourist participation of senior citizens varies considerably across Europe. It is particularly high in the Nordic countries such as Sweden and the large Western European markets. However, in most Eastern European markets, relatively few senior citizens travel. The share of older tourists is below $10 \%$ in Bulgaria, Lithuania and Slovakia, while the share of older people in the population of these countries is $16-23 \%$.

\section{METHODOLOGY}

To evaluate the quality of the tourist offer according to the needs of the market segment of senior tourists, a mixed methodology design was applied by combining quantitative and qualitative methods of data collection and processing. Quantitative data were derived from the three most important sources. The first source is based on the results of the most recent research conducted by the Institute of Tourism in Zagreb under the title "Attitudes and consumption of tourists in Croatia in 2017", which determined the most important characteristics of the quality of Croatian tourism offerings that were turned into criteria that later measured the compatibility of tourist product supply according to requirements and the preferences of the relevant market segment (see Table 1). Another important source of quantitative data was a comprehensive survey of the TOURage project, funded by the INTERREG IVC Interregional Cooperation Program under the auspices of the EU, which explored the general attitudes and preferences of the older tourists segment within the EU emissive market on individual components of the tourist supply. The third source of quantitative data is based on the conducted survey within relevant individuals representing the top 5 Croatian hotel companies to evaluate their own perception (Likert scale from 1 to 5 ) on the quality of the relevant components of tourist supply in Croatia. 
ToSEE - Tourism in Southern and Eastern Europe, Vol. 5, pp. 533-545, 2019

D. Pavlović, M. Koščak, N. Šerić: THE POTENTIAL OF CROATIA AS AN ATTRACTIVE TOURIST ...

For the verification of the aforementioned quantitative research, qualitative methodology has been used through open-ended interviews in order to obtain more comprehensive information on deficiencies, problems, limitations and suggestions for improvement in certain segments. Their perceptions about the quality of individual components of the tourist supply (products) were important for discovering any possible gap between identity and image of Croatian destinations and their tourist supply.

For the analysis and processing of the obtained quantitative data, descriptive statistical analysis (frequencies and arithmetic means) was used from structured questionnaires set up by the subjects of tourist offer in HR. Comparative analysis within the designed socalled match model yielded the most important research results (Table 2). Content analysis as a method was used in the case of processing qualitative data for each component of the tourist supply. Below is a detailed process of data processing according to the specific aims and purposes of the research in this paper:

1. To evaluate the current offer of composite tourist products in Croatia in relation to the needs of senior tourists with a focus on the European market (IC1), a comparative analysis (match model) was used, where the results of tourism research indicators were used for the tourist preferences of senior tourists TOURage (see chapters two and three) and TOMAS survey (see Chapter three) as an indicator of the quality of tourist supply in Croatia.

2. To evaluate the matching level of the perceptions of the tourist supply provider in the CRO on the quality of certain elements and the offer with the preferences of their importance manifested by senior tourists (IC2), a comparative analysis was also used in which the indicators of the previous survey were used through a semi-structured interview and the results of the above-mentioned TOURage project.

3. To evaluate the level of correlation between the attitudes and perceptions of the main providers of tourism supply in the Croatia with the level of satisfaction that tourists show towards the quality of the particular elements of this supply, a comparative analysis was also used in which the indicators of the previous survey were used through semi-structured interviews and the results of the research mentioned above TOMAS 2017. An overall assessment of the respondents' opinion on tourism products in a particular components was made.

4. Quantitative findings were verified by qualitative method of content analysis and specific additional opinions of relevant persons from tourism and hotel industry in Croatia. 
ToSEE - Tourism in Southern and Eastern Europe, Vol. 5, pp. 533-545, 2019

D. Pavlović, M. Koščak, N. Šerić: THE POTENTIAL OF CROATIA AS AN ATTRACTIVE TOURIST ...

\section{RESULTS AND DISCUSSION}

Using the appropriate methodology of data collection and processing (see previous chapter), the results were sublimated in the table 2 below, from which it was possible to make a comparative analysis (comparative model) for the segment of senior tourists demand in Croatia.

Table 2: An integral view of the research results (comparative model) for components of the senior tourists demand in Croatia

\begin{tabular}{|c|c|c|c|c|c|c|c|c|}
\hline $\begin{array}{c}\text { Supply } \\
\text { components }\end{array}$ & $\begin{array}{c}\text { The av- } \\
\text { erage } \\
\text { level of } \\
\text { general } \\
\text { expecta- } \\
\text { tions of } \\
\text { the sen- } \\
\text { ior }\end{array}$ & $\begin{array}{c}\text { The aver- } \\
\text { age level } \\
\text { of general } \\
\text { expecta- } \\
\text { tions of } \\
\text { the senior } \\
(\%)\end{array}$ & $\begin{array}{c}\text { Percep- } \\
\text { tions of } \\
\text { CRO } \\
\text { providers } \\
\text { (\%) }\end{array}$ & $\begin{array}{c}\text { Total satis- } \\
\text { faction } \\
\text { with the } \\
\text { CRO tour- } \\
\text { ist supply } \\
\mathbf{( \% )}\end{array}$ & $\begin{array}{c}\text { Ger- } \\
\text { many }\end{array}$ & $\begin{array}{c}\text { Scandina- } \\
\text { via }\end{array}$ & UK & France \\
\hline $\begin{array}{c}\text { 1. Landscape } \\
\text { 2. Security } \\
\text { and safety }\end{array}$ & 4,16 & $83,20 \%$ & $88,90 \%$ & $86,48 \%$ & $81,10 \%$ & $93,40 \%$ & $85,90 \%$ & $85,50 \%$ \\
\hline $\begin{array}{c}3 . \text { Historical } \\
\text { sights availa- } \\
\text { bility }\end{array}$ & 3,9 & $78,20 \%$ & $87,90 \%$ & $83,80 \%$ & $81,30 \%$ & $88,70 \%$ & $82,00 \%$ & $83,20 \%$ \\
\hline $\begin{array}{c}4 . \text { Quality of } \\
\text { service }\end{array}$ & 3,87 & $77,40 \%$ & $80,10 \%$ & $82,50 \%$ & $78,00 \%$ & $84,20 \%$ & $83,20 \%$ & $84,60 \%$ \\
\hline $\begin{array}{c}5 . \text { Transport } \\
\text { accessibility }\end{array}$ & 3,79 & $75,80 \%$ & $76,70 \%$ & $75,85 \%$ & $70,40 \%$ & $77,10 \%$ & $76,00 \%$ & $79,90 \%$ \\
\hline $\begin{array}{c}6 . \text { Quality of } \\
\text { hotel accom- } \\
\text { modation }\end{array}$ & 3,65 & $73,00 \%$ & $82,30 \%$ & $80,93 \%$ & $77,30 \%$ & $79,20 \%$ & $85,50 \%$ & $81,70 \%$ \\
\hline $\begin{array}{c}7 . \text { Value for } \\
\text { money }\end{array}$ & 3,64 & $72,80 \%$ & $85,60 \%$ & $70,98 \%$ & $70,90 \%$ & $73,70 \%$ & $73,90 \%$ & $65,40 \%$ \\
\hline $\begin{array}{c}8 . \text { Local cul- } \\
\text { ture presen- } \\
\text { tation }\end{array}$ & 3,61 & $72,20 \%$ & $65,40 \%$ & $61,43 \%$ & $58,50 \%$ & $58,50 \%$ & $65,30 \%$ & $63,40 \%$ \\
\hline $\begin{array}{c}9 . \text { Additional } \\
\text { experience }\end{array}$ & 3,57 & $71,40 \%$ & $59,30 \%$ & $63,08 \%$ & $64,60 \%$ & $64,30 \%$ & $66,30 \%$ & $57,10 \%$ \\
\hline $\begin{array}{c}10 . \text { Health } \\
\text { care and } \\
\text { medical ser- } \\
\text { vice }\end{array}$ & 3,49 & $69,80 \%$ & $75,60 \%$ & $\mathrm{NA}$ & $\mathrm{NA}$ & $\mathrm{NA}$ & $\mathrm{NA}$ & $\mathrm{NA}$ \\
\hline
\end{tabular}

Note: The bold font in the table is marked by dismatching; for supply elements whose perceived quality is below the expected relevance of the demand segment in question, the over-estimated quality perception of the supply by the subjects of the supply in the CRO and below the rated satisfaction rating (TOMAS research) by a tourist supply

Source: Authors of the paper 
ToSEE - Tourism in Southern and Eastern Europe, Vol. 5, pp. 533-545, 2019

D. Pavlović, M. Koščak, N. Šerić: THE POTENTIAL OF CROATIA AS AN ATTRACTIVE TOURIST ...

From the above aggregate table, it is possible analytically to read through several important conclusions that can be sublimated into several important points:

1. Elements of tourist offerings related to: accessibility and offer of historical monuments, pricing, local culture presentation and additional tourist experience of older people are below the perception of their importance and their general expectations. Exceptions are tourists from Scandinavia and Great Britain who consider the prices to be appropriate for the services offered (value for money). Based on this it can be concluded that there is a difference in the attitudes of individual country tourists in terms of individual supply elements, which can be useful in guiding promotional activities of Croatia as a tourist destination according to the relevant demand segment.

2. The perceptions of the most important subjects of tourist offer (tourist and hotel companies) on the quality of offerings for elements: natural landscape, security, offer of historical sights, quality of transport, local culture are defined in relation to the really rated quality of the same by all segments of tourists ). The exception are tourists from Scandinavian countries who rated this quality better in the elements: quality of landscapes, transport and security. The presented findings can point to a certain disparity between identity and image of Croatia in tourist terms when it comes to individual components of a complex tourism product.

3. Quality of the landscape, security, general services, hotel accommodation, transport according to the rating of all segments of tourists who visited Croatia are above the expected quality expected of older tourists for any destination, which would be particularly important in future promotional activities.

4. Analysing the content of the interviews with the relevant tourist industry representatives in Croatia and the most important preferences and characteristics of the segment of senior tourists within the European emissive market (see Chapter Two), it would be important to improve the supply in several components:

- safety of transportation and stay for older tourists with adequate medical accessibility, with adequate comfort especially for those categories of tourists at the age of $75+$

- unique experiences, combining adventure, nature and culture with educational components in contact with local community,

- $\quad$ specific niche products such as cycling, culture, wellness, culinary, shorter cruises, etc.,

- package flexible modules with different types of activities and accommodations, with different price and comfort levels, which allow older people to package arrangement according to their own needs and desires, with a detailed product / itinerary description.

In promotional activities according to the segment of senior tourists, it would be desirable to use both online and traditional media such as newspapers, television and magazines for their age. Particularly important would be to focus on the category of tourists from 65 to 74 years, within the dominant EU emission markets: Germany, France, Great Britain and Scandinavia. 
ToSEE - Tourism in Southern and Eastern Europe, Vol. 5, pp. 533-545, 2019

D. Pavlović, M. Koščak, N. Šerić: THE POTENTIAL OF CROATIA AS AN ATTRACTIVE TOURIST ...

\section{CONTRIBUTION OF THIS WORK AND RECOMMENDATIONS FOR FUTURE RESEARCH}

In summary, the contribution of this work is reflected in the scientific-methodological and applicative sense. In the scientific and methodological sense, the key contribution of the work is reflected in the application of a unique set of tools and techniques that consist of a combination of quantitative and qualitative findings of the most important stakeholders in tourism. The so-called match model, which has been used to test the compliance of tourist destination offers with the requirements and preferences of individual tourist segments, has been added to the perceptions of the main providers of tourist offers in destinations on the value and quality of its most important components, thus identifying the possible gap between identity and image of the destinations themselves.

In terms of application, this is the first work in Croatia to deal with an increasingly growing segment of senior tourists who can be very interested in expanding tourist activities, especially in terms of extending the tourist season. The methodological approach in this paper can serve to test the adequacy of tourist supply in Croatia for the senior tourists segment as well as recommendations for possible corrective actions of its alignment towards that segment.

This paper has certain limitations that are most important in a limited sample of respondents or stakeholders who have been used in this research. More specifically, in the future research (perhaps within the TOMAS survey), it should be more focused on the segment of senior tourists $(65+)$ who visit Croatia within and outside the main season within multiple destinations.

\section{CONCLUSION}

The segment of senior tourists becomes unavoidable in the consideration of tourist destinations when it comes to improving tourist activities, especially in the extension of the tourist season. Croatia, as a tourist destination characterized by high seasonality, may especially be interested in this segment of tourists. Therefore, it was important to evaluate the current supply of composite tourist products in Croatia in relation to the senior tourists segment demand with an emphasis on the European market and to identify all the deficiencies and disparities in order to make recommendations for a more efficient development of tourism products within Croatia in function of the extension of the tourism season. The results were obtained by using a mixed methodology by combining quantitative (TOMAS research from 2017 and TOURage project from 2014) and qualitative (semi-structured interview with relevant tourism industry entities in Croatia) data processing methods using comparative analysis within the match model. Recognitions and recommendations from research findings can be summarized in the following:

1. Quality of the landscape, security, general services, hotel accommodation, transport according to the rating of all segments of tourists who visited Croatia are above the quality expected of senior tourists for any destination, which would be particularly important in future promotional activities, 
ToSEE - Tourism in Southern and Eastern Europe, Vol. 5, pp. 533-545, 2019

D. Pavlović, M. Koščak, N. Šerić: THE POTENTIAL OF CROATIA AS AN ATTRACTIVE TOURIST ...

2. There is a difference in the attitudes of individual country tourists when it comes to the individual elements of the supply; the supply of historical sights and additional experience is the shortcomings highlighted by European tourists with the exception of the UK and Scandinavian emission markets, which can be useful in guiding promotional activities to specific markets.

3. In promotional activities according to the segment of senior tourists, it would be desirable to use online and traditional media for their age, with the offer of flexible package of arrangements. In particular, it would be important to focus on the category of tourists from 65 to 74 years, within the dominant EU emitting market : Germany, France, Great Britain and Scandinavia.

In accordance with the above, it is possible to conclude that Croatia as a tourist destination, with certain improvements and adjustments of the supply components on the basis of a more precise insight into the targeted tourist markets, using, inter alia, a unique set of tools and techniques used in this paper, thanks to which it can acquire predisposition for stronger market access to senior tourists.

\section{REFERENCES}

Andreua, L., Kozak, M., Avcic, N. \& Cifterd, N. (2005), "Market Segmentation by Motivationsto Travel: British Tourists Visiting Turkey”, Journal of Travel \& Tourism Marketing, 19(1), pp. 1-14.

Awaritefe, O. (2004), "Motivation and Other Considerations in Tourist Destination Choice: A Case Study of Nigeria", Tourism Geographies, an International Journal of Tourism Space, Place and Environment, 6(3), pp. 303-330.

$\mathrm{CBI}$, the Centre for the Promotion of Imports from developing countries (https://www.cbi.eu/market-information/tourism/senior-travel)

Fleischer, A. \& Pizam, A. (2002), "Tourism constraints among Israeli seniors", Annals of Tourism Research, 29(1), pp. 106-123.

Formica, S. \& Uysal, M. (2006), "Destination Attractiveness Based on Supply and Demand Evaluations: An Analytical Framework", Journal of Travel Research, 44(4), pp. 418-430.

Glover, P. \& Prideaux, B. (2009), "Implications of population ageing for the development of tourism products and destinations", Journal of Vacation Marketing, 15, pp. 25-37.

Gu, D., Zhu, H., Brown, T., Hoenig, H. \& Zeng, Y. (2016), "Tourism experiences and self-rated health among older adults in China", Journal of Aging and Health, 28(4), pp. 675-703.

Harper, S. (2014), "Economic and social implications of aging societies", Science, 346(6209), pp. 587-591.

Howse, K. (2014), "Perspective on the challenges of population ageing”, in Harper, S., and Hamblin, K. (Eds.), International Handbook on Ageing and Public Policy, Edward Elgar Publishing, pp. 13-20.

Ibrahim, E. \& Gill, J. (2005), “A positioning strategy for a tourist destination, based on analysis of customers' perceptions and satisfactions", Marketing Intelligence \& Planning, 23(2), pp. 172-188.

Lehto, X.Y., O’Leary, J.T. \& Lee, G. (2002), "Mature international travelers: An examination of gender and benefits", Journal of Hospitality \& Leisure Marketing, 9(1-2), pp. 53-72.

Meiners, N., Schwartling, U. \& Seeberger, B. (2010), "The renaissance of word-of-mouth marketing: A new standard in twenty-first century marketing management?!", International Journal of Economic Sciences and Applied Research, 3(2), pp. 79-97.

Möller, C., Weiermair, K. \& Wintersberger, E. (2007), “The changing travel behaviour of Austria's ageing population and its ipact on tourism", Tourism Review, 62(3/4), pp. 15-20.

Patterson, I. \& Balderas, A. (2018), "Continuing and Emerging Trends of Senior Tourism: A Review of the Literature", Journal of Population Ageing, pp. 1-15.

Reece, W. (2004), “Are senior leisure travelers different?”, Journal of Travel Research, 43, pp. 11-18.

Sangpikul, A. (2008), "Travel motivations of Japanese senior travellers to Thailand", International Journal of Tourism Research, 10(1), pp. 81-94.

TOMAS (2017), Attitudes and consumption of tourists in Croatia in 2017'

TOURage project, 2014, in partnership of INTERREG IVC pro-gram and the European Union. 
ToSEE - Tourism in Southern and Eastern Europe, Vol. 5, pp. 533-545, 2019

D. Pavlović, M. Koščak, N. Šerić: THE POTENTIAL OF CROATIA AS AN ATTRACTIVE TOURIST ...

Uysal, M., Perdue, R. \& Sirgy, M.J. (Eds.) (2012), Handbook of tourism and quality-of-life research Enhancing the lives of tourists and residents of host communities, Springer Science \& Business Media.

Wang, K.C., Chen, J.S. \& Chou, S.H. (2007), "Senior tourists' purchasing decisions in group package tour", Anatolia, 18(1), pp. 23-42.

Yoon, C., Cole, C. \& Lee, M. (2009), "Consumer decision making and aging: Current knowledge and future directions", Journal of Consumer Psychology, 19(1), pp. 2-16.

Damir Pavlović, $\mathrm{PhD}$, Senior Lecturer

LIBERTAS, International University

Trg J.F. Kennedy 6b, 10000 Zagreb, Croatia

Phone: 0038512442595

E-mail: damir.pavlovic@ zg.t-com.hr; dpavlovic1@libertas.hr

Marko Koščak, PhD, Assistant Professor

University of Maribor, Faculty of Tourism

Cesta prvih borcev 36, 8250 Brežice, Slovenija

Phone: +38640202898

E-mail: marko.koscak@um.si

Nikolina Šerić, M. Econ., Assistant

University of Rijeka, Faculty of Tourism and Hospitality Management

Tourism Department

Ika, Primorska 42, p.p. 97, 51410 Opatija, Croatia

Phone: 0038551294183

E-mail: nseric@fthm.hr 